\title{
Localization and Characterization of a Gene on the ColE3-CA38 Plasmid that Confers Immunity to Colicin E8
}

\author{
By KIN-FU CHAK AND RICHARD JAMES* \\ School of Biological Sciences, University of East Anglia, Norwich NR4 7TJ, UK
}

(Received 2 September 1983; revised 18 October 1983)

\begin{abstract}
Escherichia coli W3110 cells carrying the ColE3-CA38 plasmid are immune to externally added colicin E8, a newly described member of the $\mathrm{E}$ group colicins. By molecular cloning and transposon mutagenesis we localized the colicin E8 immunity gene between the EcoRI site (4.0 kb on the restriction map) and the PvuII site $(3.68 \mathrm{~kb})$ of the ColE3-CA38 plasmid. This placed the colicin E8 immunity gene between the colicin E3 immunity gene and lys, the region which determined mitomycin $C$ sensitivity. Insertion of a transposon into the colicin E3 structural gene prevented the synthesis of active colicin and completely abolished mitomycin $\mathrm{C}$ sensitivity, but had no effect on the two immunity genes. In contrast, insertion of a transposon into the colicin E8 immunity gene had no effect upon colicin E3 production or colicin E3 immunity but did abolish mitomycin $\mathrm{C}$ sensitivity. The phenotype conferred by plasmids with a transposon inserted into the lys region of ColE3-CA38 was dependent upon the site of insertion.
\end{abstract}

\section{INTRODUCTION}

The E colicins are a group of plasmid-coded, antibacterial proteins which use the same receptor (Fredericq, 1949), the gene product of the Escherichia coli chromosomal gene btuB, to bind to sensitive $E$. coli cells (Di Masi et al., 1973). They are inducible proteins, the synthesis of which is triggered by DNA damage of the host cell (Herschman \& Helinski, 1967). This group may be subdivided into colicin E1 to E7 on the basis of immunity tests (Watson et al., 1981). Each $\mathrm{E}$ colicin plasmid codes for the production of a specific immunity protein which protects the host cell against colicin of the same type, either during production or if added externally. For example, cells carrying the ColE3-CA38 plasmid are immune to external colicin E3 but not to colicin E1 or E2. Escherichia coli K12 strains carrying an E colicin plasmid are also mitomycin C sensitive compared to plasmid-free isogenic strains. This is presumed to be the result of induction of a third plasmid-coded gene which may be involved in cell lysis and subsequent colicin release from the producing cell (Shafferman et al., 1979; Sabik et al., 1983). Since immunity appears to be constitutive, whilst colicin production and mitomycin $\mathrm{C}$ sensitivity are inducible by DNA damage (Herschman \& Helinski, 1967), the regulatory control of these three genes in response to DNA damage is of considerable interest.

A new member of the $\mathrm{E}$ group of colicins, designated colicin E8, has recently been described (Cooper \& James, 1984). Escherichia coli K12 strains carrying the ColE3-CA38 plasmid exhibit a novel non-reciprocal immunity against colicin E8. Whilst E. coli K12(ColE3-CA38) strains are immune to externally added colicin E8, E. coli $\mathrm{K} 12$ (ColE8-J) strains are sensitive to externally added colicin E3. Here we show that the ColE3-CA38 plasmid carries a gene coding for colicin E8 immunity. The localization and characterization of this immunity gene by molecular cloning and transposon mutagenesis provides information on the regulation of the colicin operon. Our data on the regulation of the two immunity genes present on the ColE3-CA38 plasmid are consistent with that suggested for the regulation of the colicin E3 immunity gene derived from the DNA sequence of part of the ColE3-CA38 plasmid (Masaki \& Ohta, 1982; Mock et al., 1983). 


\section{METHODS}

Strains and media. Escherichia coli W3110 ColE3-CA38 (PRC595) and E. coli W3110 ColE2-P9 (PRC594) were kindly supplied by the Plasmid Reference Centre, Stanford, Ca., USA). Escherichia coli W3110 ColE8-J has previously been described (Cooper \& James, 1984). Escherichia coli RB85 $\mathrm{F}^{-}$thr leu lac $Y$ strA supE44 tonA and $E$. coli $\mathrm{RB} 308 \mathrm{~F}^{+}$thr leu thy A deoC lac $Y$ were obtained from $\mathrm{R}$. S. Buxton. The sex factor in the latter strain is the source of the transposon Tn1000 (Buxton \& Drury, 1983). The properties and derivation of the plasmids used are described in Fig. 1. Escherichia coli JM83 ara lac pro thi strA $\phi 80 \mathrm{~d} / a c Z$ M15 was used as the host strain for transformations using the vector pUC8, and was kindly supplied by BRL. Escherichia coli W3110 was used as the host strain for transformations using the vector pBR322.

Bacteria were cultured at $37^{\circ} \mathrm{C}$ in LB broth (Miller, 1972). For selection of recombinant clones, antibiotics were included in LB agar (LB broth containing $1.5 \% \mathrm{w} / \mathrm{v}$, agar) at the following final concentrations; ampicillin, $50 \mu \mathrm{g} \mathrm{ml}{ }^{-1}$; tetracycline, $10 \mu \mathrm{g} \mathrm{ml}^{-1}$; kanamycin, $25 \mu \mathrm{g} \mathrm{ml}^{-1}$; streptomycin $200 \mu \mathrm{g} \mathrm{ml}^{-1}$. The chromogenic substrate 5-bromo-4-chloro-3-indolyl- $\beta$-D-galactoside (X-gal) was used to select pUC8 recombinants and was included in LB agar at a final concentration of $20 \mu \mathrm{g} \mathrm{m} \mathrm{m}^{-1}$.

Preparation of colicin extracts. Colicin E2, E3 and E8 extracts were prepared from cultures of $E$. coli W3110 E2P9 (PRC594), E. coli W3110 E3-CA38 (PRC595) and E. coli W3110 ColE8-J, respectively. Overnight cultures were diluted in $50 \mathrm{ml} \mathrm{LB}$ and grown to an $O D_{\text {s so }}$ of 0.2 before addition of mitomycin $C\left(0.5 \mu \mathrm{g} \mathrm{ml}^{-1}\right)$. After $4 \mathrm{~h}$ incubation, chloroform was added and incubation continued for $15 \mathrm{~min}$ at $37^{\circ} \mathrm{C}$. Any remaining cells were removed by centrifugation at $10000 \mathrm{~g}$ for $15 \mathrm{~min}$. The aqueous phase was then removed and stored in portions at $-20^{\circ} \mathrm{C}$. LB agar plates containing colicin extracts were prepared by spreading $0.2 \mathrm{ml}$ of the appropriate extract over the surface of the plate.

Colicin production and immunity tests. Colicin production was determined by stab tests (Kennedy, 1971), using E. coli W3110 as the sensitive indicator strain. Colicin E8 immunity was scored as resistance to colicin E8 but sensitivity to colicin E2 or E3. Similarly, colicin E3 immunity was scored as resistance to colicin E3 but sensitivity to colicin E2 and E8. This was tested by streaking a loopful of a broth culture onto LB agar plates containing extracts of colicin E2, E3 or E8.

Colicin titres. Colicin titres were determined by a modification of the method of Reeves (1965) developed by G. M. P. Lawrence.

Plasmid isolation. For screening of recombinants, plasmids were prepared by the method of Hopwood et al. (1983). For endonuclease restriction and transformation, plasmids were prepared by a modification of the method of Birnboim \& Doly (1979).

Two plasmid vectors were used for the isolation of recombinant clones, pBR322, which is $4.36 \mathrm{~kb}$ in size and confers ampicillin and tetracycline resistance (Sutcliffe, 1978), and pUC8, which is $2.7 \mathrm{~kb}$ in size and carries single cloning sites for a number of restriction endonucleases within a 'polylinker' inserted close to the $\mathrm{N}$-terminus of a fragment of the $\beta$-galactosidase gene (Vieira \& Messing, 1982). Insertion of recombinant DNA in the polylinker prevents $\alpha$ complementation with the defective lacZ gene carried by $E$. coli JM83.

Restriction, ligation and transformation. Digestion of DNA with restriction endonucleases, ligation of DNA fragments and transformation of competent cells were carried out as previously described (Maniatis et al., 1982).

Electrophoresis of DNA. The sizes of DNA fragments were analysed by gel electrophoresis in $0.8 \%$ or $1.0 \%$ ( $w / v)$ agarose. Tris/acetate or Tris/borate buffers were used depending upon the sizes of the fragments (Maniatis $e t$ al., 1982). Lambda DNA digested with HindIII or PstI was used as molecular weight markers. Fragment sizes were computed from a least-squares fit of the mobility of the molecular weight markers using a program developed by one of us (R.J.) on a BBC microcomputer model B.

Mitomycin $C$ sensitivity. For screening the mitomycin $C$ sensitivity of large numbers of recombinants we devised a microtitre assay in which $10 \mu$ l volumes of cultures were added to $190 \mu \mathrm{l}$ pre-warmed LB, containing mitomycin $C\left(0.5 \mu \mathrm{g} \mathrm{ml}{ }^{-1}\right)$, in a microtitre dish. The initial optical density values of all 96 wells in a tray were then read using a Titertek Multiscan MC plate reader at $540 \mathrm{~nm}$. The microtitre plate was then gently shaken at $37^{\circ} \mathrm{C}$ and the optical density values were read at hourly intervals for $6 \mathrm{~h}$ and then again after $24 \mathrm{~h}$. Control cultures of $E$. coli W 3110 reached stationary phase at optical density values of about $0 \cdot 5$, whilst mitomycin-sensitive cultures lysed at an optical density value of about $\mathbf{0 . 2}$. Using this method it was feasible to screen several hundred recombinant colonies in one day. Cultures which exhibited a delayed lysis in the microtitre assay were studied further in the shaken flask assay. Overnight cultures were diluted 50 -fold into $50 \mathrm{ml} \mathrm{LB}$ in a $100 \mathrm{ml}$ flask and were incubated with shaking at $37^{\circ} \mathrm{C}$ until the $O D_{s, 0}$ reached 0.3 to 0.4 . At this time $20 \mathrm{ml}$ of the culture was transferred to a second flask to which mitomycin $C\left(0.5 \mu \mathrm{g} \mathrm{ml}^{-1}\right)$ was added. The optical density readings of both flasks were taken at intervals up to $6 \mathrm{~h}$.

Transposon mutagenesis. Transposon mutagenesis of plasmids pKC10, $\mathrm{pKC11}$ and $\mathrm{pKC} 22$ carried out using the method of Tommassen et al. (1982). Cultures of $E$. coli W3110 carrying the appropriate plasmid were grown up overnight in LB supplemented with ampicillin and maltose $(0 \cdot 2 \%, w / v)$. The cells were collected by centrifugation and concentrated threefold in $0.9 \%(w / v) ~ N a C l, 20 ~ m u-\mathrm{MgCl}_{2}$. After $45 \mathrm{~min}$ incubation at $37^{\circ} \mathrm{C}, 10 \mu \mathrm{l}$ of phage 
lambda b221 c1857 rex:: $\operatorname{Tn} 5$ was added to $0.1 \mathrm{ml}$ volumes of cells at a multiplicity of infection of 10 . The mixtures were incubated at $30^{\circ} \mathrm{C}$ for $30 \mathrm{~min}$ then diluted 100 -fold in LB containing ampicillin and grown overnight at $30^{\circ} \mathrm{C}$. Subsequently the cultures were diluted 100 -fold in LB containing ampicillin, kanamycin and sodium citrate $(0.1 \%, \mathrm{w} / \mathrm{v})$ and grown overnight at $30^{\circ} \mathrm{C}$. Plasmid DNA was isolated from the overnight culture and was used to transform $E$. coli W3110, selecting for $\mathrm{Amp}^{\mathrm{R}} \mathrm{Kan}^{\mathrm{R}}$ transformants. Colonies were picked and grown overnight in $200 \mu \mathrm{l} \mathrm{LB}$ containing ampicillin and kanamycin in microtitre dish wells. To maintain selection pressure for the presence of $\mathrm{Tn} 5$ we routinely included kanamycin in all growth media. Tn 1000 transposon mutagenesis was carried out by transforming plasmid pKC10, pKC11 or pKC22 into $E$. coli $\mathrm{RB} 308$ which is $\mathrm{F}^{+}$. These donor strains were then grown overnight in LB containing ampicillin whilst the recipient strain $E$. coli $R B 85$ was grown in LB. After diluting 50-fold in LB, the cultures were grown with gentle shaking at $37^{\circ} \mathrm{C}$ for 2 to $3 \mathrm{~h}$, at which time $0.1 \mathrm{ml}$ donor culture was mixed with $1.0 \mathrm{ml}$ recipient culture and incubated without shaking for $1 \mathrm{~h}$ at $37^{\circ} \mathrm{C}$. The mating mixture was then diluted into $4 \mathrm{ml} \mathrm{LB}$ containing streptomycin and incubation continued with vigorous aeration for $2 \mathrm{~h}$. The culture was then diluted and plated on LB agar containing streptomycin and ampicillin to select for mobilization of pKC10, pKC11 or pKC22.

Transposon insertion sites were located by isolating plasmid DNA and restricting separately with a group of restriction endonucleases. For TnS inserts, BamHI, HindIII and Sall were employed to analyse the location and the orientation of the insertions (Jorgensen et al., 1979), while for Tn1000, EcoRI alone was usually sufficient to determine the location and orientation (Guyer, 1978).

\section{RESULTS}

\section{Analysis of recombinant plasmids}

A partial EcoRI digest of the ColE3-CA38 plasmid and subsequent ligation into the EcoRI site of $\mathrm{pBR} 322$ yielded recombinant plasmid $\mathrm{pKC11}$ which carried the whole $7.2 \mathrm{~kb}$ ColE3CA38 plasmid. A restriction map of plasmid pKC11 was obtained after single and double digests with a range of restriction endonucleases. The restriction sites in the ColE3-CA38 portion of plasmid pKC11 are shown in Fig. 1. Transformants of $E$. coli W31 10 carrying plasmid pKC11 were immune to colicin E3 and colicin E8. In contrast, plasmid pKC10, which carried the $3.12 \mathrm{~kb}$ EcoRI fragment of ColE3-CA38 ligated into pBR322, conferred immunity to colicin E3 but not to colicin E8. Escherichia coli W3110, when transformed with plasmids pKC13 or pKC14, in which XhoI-restricted ColE3-CA38 DNA was ligated into the SalI site of pBR322 in either orientation, were immune to colicin $\mathrm{E} 3$ but were sensitive to colicin $\mathrm{E} 8$. The recombinant plasmid pKC25, in which the $2.76 \mathrm{~kb}$ SmaI-PvuII fragment of ColE3-CA38 was ligated into the HincII site of pUC8, conferred immunity to both colicin E3 and E8. The structures of these recombinant plasmids placed the colicin E8 immunity gene between the PvuII site $(3.68 \mathrm{~kb}$ on the restriction map and the EcoRI site $(4.08 \mathrm{~kb})$ of the ColE3-CA38 plasmid, and indicated that it was cut by $X h o I$.

\section{Transposon mutagenesis}

The transformants resulting from $\operatorname{Tn} 5$ mutagenesis and the transconjugants from $\operatorname{Tn} 1000$ mutagenesis were screened for the insertional inactivation of colicin production, colicin E8 immunity and mitomycin $\mathrm{C}$ sensitivity as described above. With $\mathrm{Tn} 5$, the frequency of inserts which inactivated colicin production, colicin E8 immunity or mitomycin C sensitivity was $21 \%$. For $\operatorname{Tn} 1000$, the frequency of transconjugants in which the transposon had inactivated one of the three phenotypic characters was $12 \%$. The phenotypes conferred by the mutant plasmids used in this work are shown in Table 1 . We were unable to isolate a transposon insert which abolished colicin E3 immunity, even with plasmid pKC22 which does not produce active colicin E3.

(a) Localization of the colicin E8 immunity region. With plasmid $\mathrm{pKC11}$ we obtained three independent transpositions of Tn 1000 that inactivated colicin E8 immunity (Fig. 2a). In an attempt to increase the frequency of transposition into this relatively small target region we repeated the transposition using plasmid pKC22 which lacked the $2.1 \mathrm{~kb}$ ClaI fragment of pKC11. Three more transposons in the colicin E8 immunity region were isolated with this plasmid (Fig. $2 b$ ). Using pKC11 we did not obtain any Tn5 transpositions into the colicin E8 immunity region but four independent inserts in this region were obtained with plasmid pKC22 


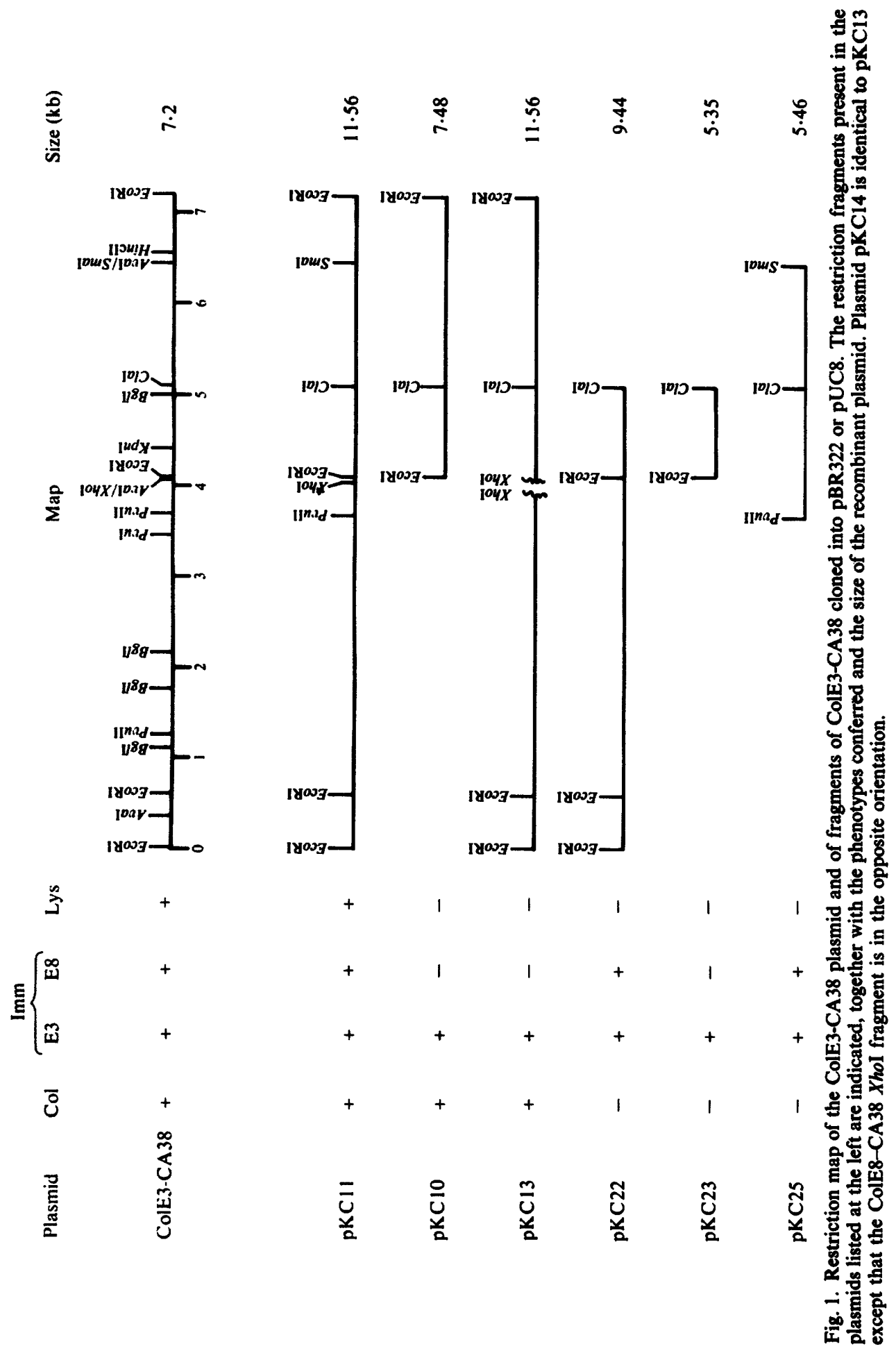



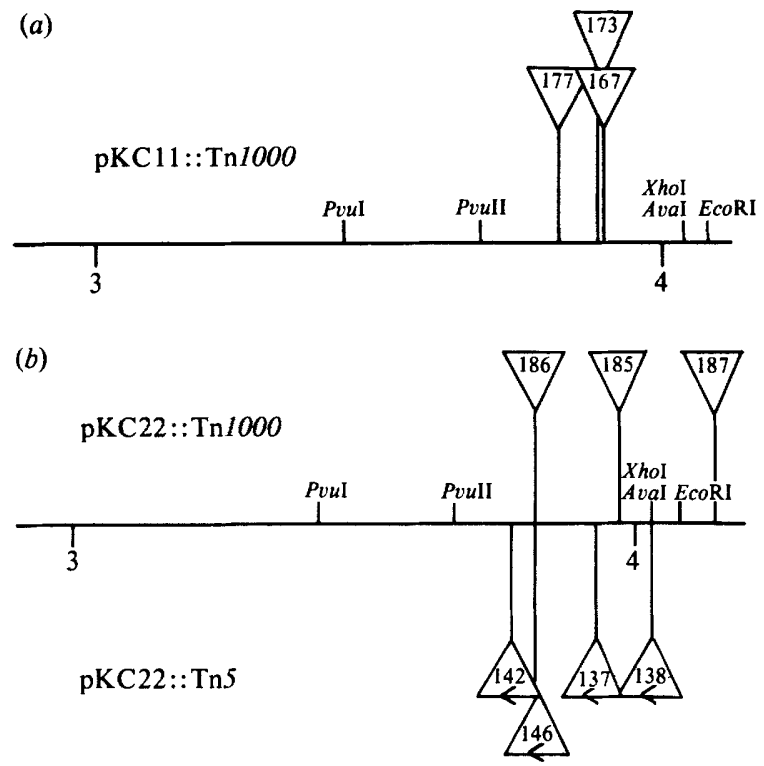

Fig. 2. (a) Insertion sites of $\mathrm{Tn} 1000$ in plasmid pKC11 which inactivate colicin E8 immunity. Only the relevant part of the restriction map of pKC11 is shown. (b) Insertion sites of $\mathrm{Tn} 1000$ (above the line) and $\mathrm{Tn} 5$ (below the line) in plasmid pKC22 which inactivate colicin E8 immunity. For Tn5 the arrow shows the orientation of the transposon.

\section{Table 1. Phenotypes of plasmids carrying transposon inserts}

Phenotypes conferred by plasmids with transposon inserts which inactivate colicin production, colicin E8 immunity or mitomycin $C$ sensitivity. Partial mitomycin $C$ sensitivity is recorded as $+/-$.

\begin{tabular}{|c|}
\hline Plasmid \\
\hline 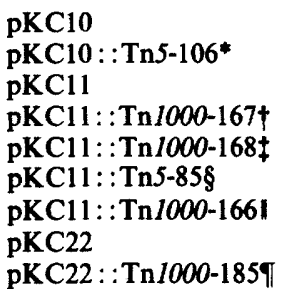 \\
\hline
\end{tabular}

\begin{tabular}{cccc}
\multicolumn{4}{c}{ Phenotype } \\
Col & ImmE3 & ImmE8 & Lys \\
+ & + & - & - \\
- & + & - & - \\
+ & + & + & + \\
+ & + & - & - \\
- & + & + & - \\
- & + & + & - \\
+ & + & + & $+1-$ \\
- & + & + & - \\
- & + & - & -
\end{tabular}

* Transposon inserts $\operatorname{Tn} 5-107,111,113,120$ and 122 confer the same phenotype. $\uparrow$ Transposon inserts $\mathrm{Tn} 1000-173$ and 177 confer the same phenotype.

$\ddagger$ Transposon inserts $T n 1000-170,171,182$ and 184 confer the same phenotype.

8 Transposon inserts Tn5-89, 90, 92 and 96 confer the same phenotype.

I Transposon inserts $\operatorname{Tn} 1000-172$, Tn5-87 and 91 confer the same phenotype.

Tा Transposon inserts $\mathrm{Tn} 1000-186,187$ and $\mathrm{Tn} 5-138,142$ and 146 confer the same phenotype.

(Fig. $2 b$ ). The above data confirm the localization of the colicin E8 immunity gene of the ColE3CA38 plasmid to a $320 \mathrm{bp}$ site which includes the $X h o I$ and EcoRI restriction sites.

(b) Localization of the colicin E3 structural gene. The phenotype conferred by plasmid pKC10 localized the colicin E3 structural gene on the 3.12 kb EcoRI fragment of ColE3-CA38. With pKC11 we obtained five independent transpositions of $\operatorname{Tn} 1000$ and of $\operatorname{Tn} 5$ which prevented the synthesis of active colicin E3. The map positions and orientations of these insertions are shown in Fig. 3(a). A further six independent transpositions of Tn5 which inactivated colicin E3 


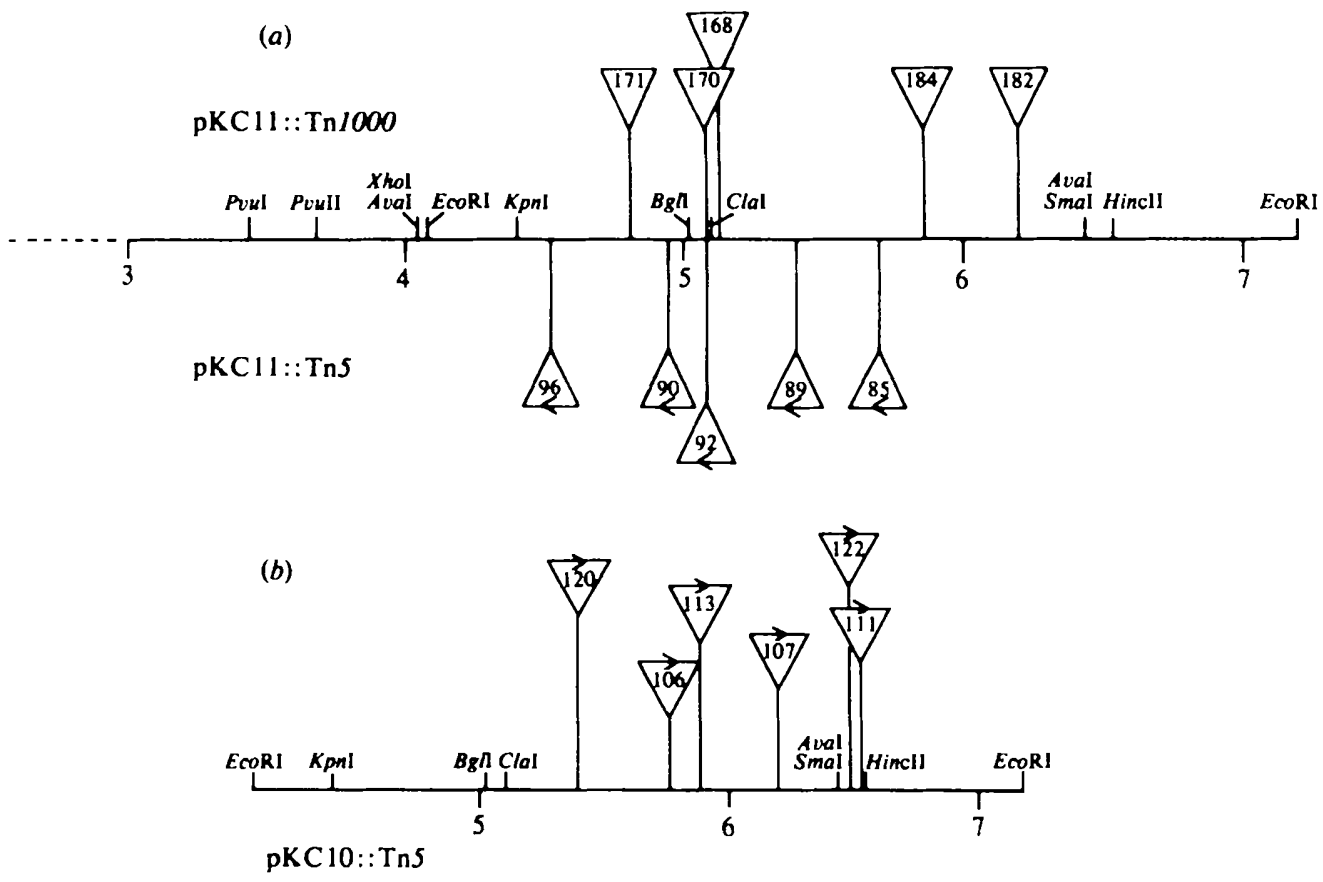

Fig. 3. (a) Insertion sites of $\mathrm{Tn} 1000$ and $\mathrm{Tn} 5$ in plasmid pKC11 which inactivate colicin E3 production. (b) Insertion sites of $\mathrm{TnS}$ in plasmid pKC10 which inactivate colicin E3 production.

production were obtained with pKC10 (Fig. $3 b$ ). The sites of insertion of some of this latter group were significantly different to those obtained in pKC11, two of them being located between the SmaI and HimcII restriction sites.

(c) Localization of the mitomycin $C$ sensitivity region. A comparison of the mitomycin $C$ sensitivity encoded by a number of recombinant plasmids is shown in Fig. 4. Plasmid pKC11 conferred a considerably enhanced mitomycin $C$ sensitivity compared to plasmid pKC10 in $E$. coli $\mathrm{W} 3110$. We obtained two independent insertions of $\operatorname{Tn} 5$ and of $\mathrm{Tn} 1000$ which significantly reduced the mitomycin $\mathrm{C}$ sensitivity (in the microtitre assay) associated with the presence of plasmid pKC11 in E. coli W3110. These insertions mapped in a 200 bp region which included the PvuI and the PvuII restriction sites (Fig. 5). The mitomycin C sensitivities of two of these strains are shown in Fig. 4 and were intermediate compared to $E$. coli $\mathrm{W} 3110(\mathrm{pKC10})$ and $E$. coli W3110(pKC11). The presence of a transposon in the mitomycin $\mathrm{C}$ sensitivity region of plasmid pKC11 had a dramatic effect upon the release of colicin from mitomycin $\mathrm{C}$ induced cells (Table 2). A comparison of the data for plasmids pKC10 and $\mathrm{pKCl1}$ shows a dramatic change in the ratio of intracellular and extracellular colicin $3 \mathrm{~h}$ after mitomycin $\mathrm{C}$ induction. The total colicin titre was also consistently lower in cultures carrying plasmid pKC10 as compared to pKC11. Plasmid pKC11 : :Tn5-87 gave essentially the same results as plasmid pKC10, whilst the results with pKC11::Tn5-91 were similar to those with plasmid pKC11::Tn5-87 at 1 or $3 \mathrm{~h}$ after induction, but changed dramatically at $5 \mathrm{~h}$.

\section{Regulation of the colicin E3 operon}

Our results with transposon mutagenesis clearly showed that inactivation of the colicin E3 structural gene completely abolished mitomycin sensitivity (Table 1), without affecting colicin E3 or colicin E8 immunity. Similarly, insertion of a transposon into the colicin E8 immunity gene also abolished mitomycin sensitivity, but did not affect colicin E3 immunity or colicin E3 production. In contrast, a transposon inserted into the mitomycin $C$ sensitivity gene did not affect colicin E3 or colicin E8 immunity, or colicin E3 production. These results suggest that the 


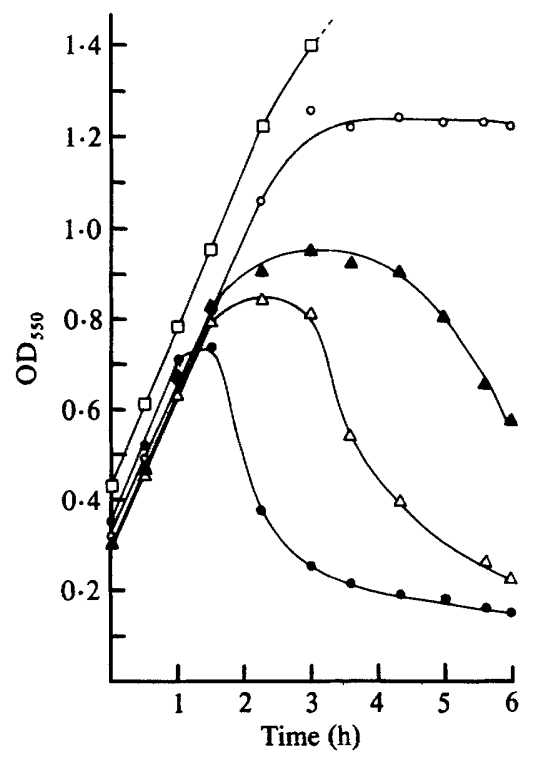

Fig. 4. Effect of mitomycin C on growth of $E$. coli W3110 carrying plasmids $\mathrm{pBR} 322(\square)$, pKC10 (O), pKC11 (O), pKC11::Tn5-87 ( $\Delta)$ and pKC11 ::Tn5-91 $(\Delta)$. For the sake of clarity the control curves, which were essentially identical for all five cultures, are omitted from the Figure.

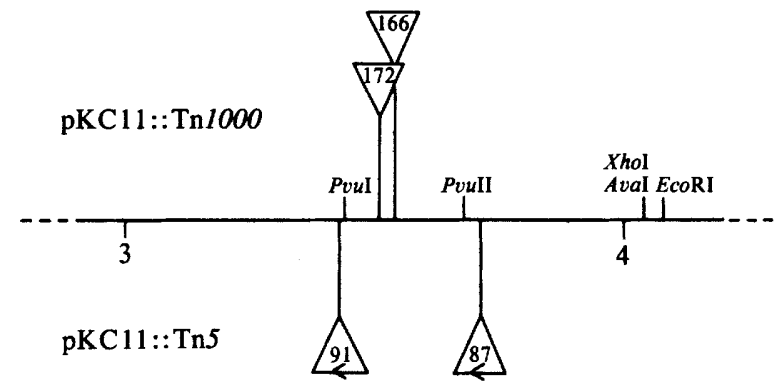

Fig. 5. Insertion sites of $\mathrm{Tn} 1000$ and $\mathrm{Tn} 5$ in plasmid pKC11 which reduce mitomycin $\mathrm{C}$ sensitivity.

Table 2. Colicin titres in mitomycin $C$ induced cultures

Colicin titres of $E$. coli W3110 carrying the plasmid indicated at 1,3 and $5 \mathrm{~h}$ after mitomycin $\mathrm{C}$ induction.

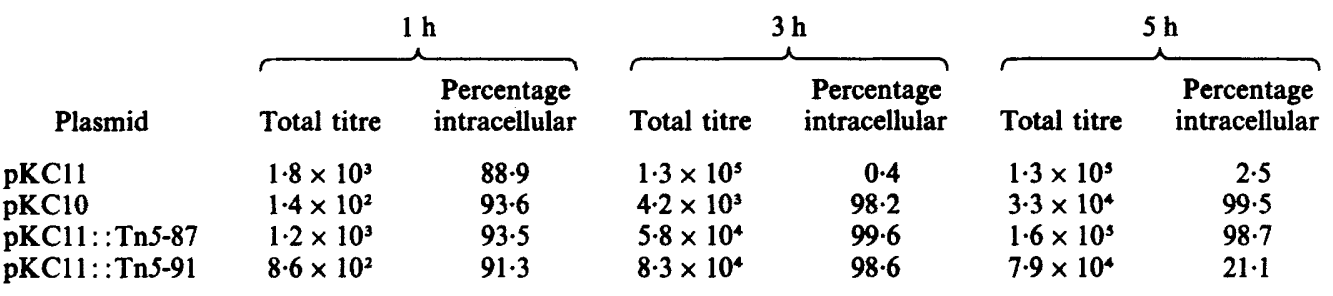

two immunity genes have their own promoter(s). Digestion of plasmid pKC11 ::Tn5-96, which has the transposon inserted $110 \mathrm{bp}$ to the right of the KpnI site, with SaII and re-ligation removes a $3.32 \mathrm{~kb}$ Sall fragment from within $\mathrm{Tn} 5$ to the $S a l l$ site in the vector. The resulting plasmid pKC32 still conferred immunity both to colicin E3 and E8. 


\section{DISCUSSION}

We have demonstrated, by subcloning fragments of plasmid ColE3-CA38, that the nonreciprocal immunity of $E$. coli $W 3110$ carrying this plasmid against a colicin E8 producing strain (Cooper \& James, 1984) is due to the presence of a colicin E8 immunity gene. Whilst a similar non-reciprocal immunity between $E$. coli W3110 carrying the ColE7-plasmid and colicin E2 producing strains has previously been reported (Males \& Stocker, 1980), that was the result of the presence of a second plasmid conferring colicin $\mathrm{E} 2$ immunity but not production, along with the ColE7 plasmid (Watson et al., 1981). This is the first example amongst the E group colicin plasmids of two immunity genes being found on the same plasmid. The colicin E8 immunity gene has been localized to a 320 bp region of the ColE3-CA 38 plasmid. A piece of DNA this size could code for a protein of approximately $12500 \mathrm{Dal}$. This coding capacity is consistent with the molecular weight of 9500 reported for the colicin E3 immunity protein (Sidikaro \& Nomura, 1974), together with a promoter or any regulatory sequences. The colicin E8 immunity gene of the ColE8-J plasmid is found in an identical location to that in ColE3-CA38, being cut by both $X$ hoI and EcoRI restriction enzymes (G. M. P. Lawrence \& R. James, unpublished).

The minimum size of the colicin E3 structural gene, which may include promoter and regulatory sequences, is defined by the insertion site of pKC11::Tn5-96, at $110 \mathrm{bp}$ to the right of the single KpnI site, and the insertion site of pKC10::Tn5-111, at 7 bp to the left of the single HincII site, to be $2.03 \mathrm{~kb}$. A piece of DNA this size has a coding capacity for a protein of approximately $75000 \mathrm{Dal}$, which is somewhat larger than the reported size of colicin E3 (Jakes \& Zinder, 1974). The C-terminal sequence of the colicin E3 structural gene has recently been published (Masaki \& Ohta, 1982; Mock et al., 1983), and is consistent with our data. The location of the promoter and the $\mathbf{N}$-terminus of the structural gene are as yet unreported. We do not know if the isolation of plasmid pKC10 with transposition sites between the SmaI and HincII sites, significantly further to the right than any transposition sites obtained in plasmid pKC11, is related to the reduced target size of the insert in recombinant plasmid pKC10, or whether the absence of the $3.47 \mathrm{~kb}$ EcoRI fragment, which includes the mitomycin C sensitivity region, has a more direct effect on the transposon mutants of the structural gene which are viable.

Insertion of a transposon into the mitomycin $\mathrm{C}$ region of the ColE3-CA38 plasmid only partially abolished the mitomycin $\mathrm{C}$ sensitivity (Fig. 5). In contrast, the absence of this region in recombinant plasmid pKC10 completely abolished mitomycin C sensitivity (Fig. 4), as does insertion of a transposon into the colicin $\mathrm{E} 3$ structural gene, or into the colicin E8 immunity gene (Table 1). The physiological role of this region of $E$ colicin plasmids is open to debate. Sabik $e t$ al. (1983) have identified a region of the ColEl plasmid, which they call $k i l$, which appears to be required for cell lysis and colicin release after mitomycin $\mathrm{C}$ induction. The insertion of a transposon into the kil region of ColEl abolished mitomycin $\mathrm{C}$ sensitivity and colicin release from cells. Watson \& Visentin (1982), using zone sizes produced by strains carrying recombinant plasmids of ColE3-CA38 lacking the PouI to EcoRI region, which includes our $200 \mathrm{bp}$ DNA sequence, have designated this region as hic, for high colicin production on solid media. Our results on the total colicin titre of cultures carrying plasmids pKC10 and $\mathrm{pKC} 11$ are consistent with some role of this region in colicin production (Table 2); however, we have observed no difference in the sizes of the zones of inhibition produced by $E$. coli W3110 carrying either pKC10, pKC11, pKC11 ::Tn5-87, or pKC11::Tn5-91 after chloroform lysis of the producing stab (K.-F. Chak, unpublished). We are continuing our study of this region of ColE3-CA38 in order to determine the number of gene products and their physiological role in colicin induction and release.

The genetic regulation of colicin E3 production and immunity, colicin E8 immunity and mitomycin sensitivity may be partially inferred from our data on the phenotypes conferred by plasmids carrying transposon insertions (Table 1). The colicin E3 structural gene, or its regulatory sequences, presumably begins in the $100 \mathrm{bp}$ SmaI to HincII fragment of ColE3-CA38 and transcribes towards the two immunity genes and the mitomycin $\mathrm{C}$ sensitivity gene. The two immunity genes must have their own promoter(s), whilst the mitomycin $\mathrm{C}$ sensitivity gene is transcribed from the structural gene promoter. Masaki \& Ohta (1982) and Mock et al. (1983) 
claim that the colicin E3 immunity gene is transcribed in the same direction as the colicin E3 structural gene, with a possible promoter site for the immunity gene located in the colicin structural gene. An active promoter within the colicin E3 structural gene is supported by the phenotype of $E$. coli W3110(pKC11::Tn5-96), which has the transposon inserted 110 bp to the right of the KpnI site. Although this transposon is oriented such that its own promoter could transcribe through into the colicin E3 immunity gene (Berg et al., 1980), we think that this is unlikely because removal of the Tn 5 promoter by digestion of pKC11::Tn $5-96$ with Sall does not abolish colicin E3 or colicin E8 immunity. The location of the promoters for the two immunity genes along with their regulation independently of the flanking colicin E3 structural gene and the mitomycin $C$ sensitivity region of the ColE3-CA38 plasmid remains an unanswered question. The presence of two immunity genes on an $\mathrm{E}$ colicin plasmid perhaps reflects an intermediate state in the evolution of colicin plasmids. Our findings mean that some caution must be used in classifying $E$ colicins on the basis of their activity against reference cultures. Unless the panel of indicator strains carry recombinant plasmids containing single colicin immunity genes there remains possible ambiguity in the identification of $\mathrm{E}$ colicins.

We wish to thank Pearl Cooper and Tobias Kieser for helpful discussions of this work, Val Cossey for typing the smanuscript and Jill Debbage for preparation of the Figures. Kin-Fu Chak is the recipient of a Science and Engineering Research Council Studentship.

\section{REFERENCES}

Berg, D. E., Weiss, A. \& Crossland, L. (1980). Polarity of Tn5 insertion mutation in E. coli. Journal of Bacteriology 142, 439-446.

BiRnBoim, H. C. \& DOLY, J. (1979). A rapid alkaline extraction procedure for screening plasmid DNA. Nucleic Acids Research 7, 1513-1523.

BUXTON, R. S. \& DRURY, L. S. (1983). The transposon $\gamma \delta(\operatorname{Tn} 1000)$ codes for a polypeptide, with an apparent molecular weight of 72000 , which is visible in maxi-cells. FEMS Microbiology Letters 7, 287290.

COOPER, P. C. \& JAMES, R. (1984). Two new E colicins, E8 and E9, produced by a strain of Escherichia coli. Journal of General Microbiology 130, 209-215.

Di Masi, R. D., White, J. C., Schnartman, C. A. \& Bradbeer, C. (1973). Transport of vitamin B12 in $E$. coli: common receptor sites for vitamin B12 and the $E$ colicins on the outer membrane of the cell envelope. Journal of Bacteriology 115, 506-573.

FredericQ, P. (1949). Sur la resistance croisée entre colicine E et bactériophage II. Comptes rendus des séances de la Société de biologie 143, 1011-1013.

GUYER, M. S. (1978). The $\gamma \delta$ sequence of $F$ is an insertion sequence. Journal of Molecular Biology 126, 347-365.

Herschman, H. R. \& Helinski, D. R. (1967). Comparative study of the events associated with colicin induction. Journal of Bacteriology 94, 691699.

Hopwood, D. A., KIESER, T., Wright, H. M. \& BibB, M. J. (1983). Plasmids, recombination and chromosome mapping in Streptomyces lividans 66. Journal of General Microbiology 129, 2257-2269.

JAKES, K. S. \& ZINDER, N. D. (1974). Highly purified colicin E3 contains immunity protein. Proceedings of the National Academy of Sciences of the United States of America 71, 3380-3384.

Jorgensen, R. A., Rothstein, S. J. \& ReZnikoff, W.
S. (1979). A restriction enzyme cleavage map of $\operatorname{Tn} 5$ and location of a region encoding neomycin resistance. Molecular and General Genetics 177, 65-72.

KENNEDY, C. K. (1971). Induction of colicin production by high temperature or inhibition of protein synthesis. Journal of Bacteriology 108, 10-19.

MALES, B. M. \& StOCKer, B. A. D. (1980). Escherichia coli $\mathrm{K} 317$, formerly used to define colicin group E2, produces colicin E7, is immune to colicin E2, and carries a bacteriophage-restricting conjugative plasmid. Journal of Bacteriology 144, 524-531.

Maniatis, T., Fritsch, E. F. \& SAMBroOK, J. (1982). Molecular Cloning: A Laboratory Manual. Cold Spring Harbor, New York: Cold Spring Harbor Laboratory.

MASAKI, H. \& OHTA, T. (1982). A plasmid region encoding the active fragment and the inhibitor protein of colicin E3-CA38. FEBS Letters 149, 129132.

MILler, J. H. (1972). Experiments in Molecular Genetics. Cold Spring Harbor, New York: Cold Spring Harbor Laboratory.

Mock, M., MiYada, C. G. \& Gunsalus, R. P. (1983). Nucleotide sequence for the catalytic domain of colicin E3 and its immunity protein. Evidence for a third gene overlapping colicin. Nucleic Acids Research 11, 3547-3557.

ReEves, P. (1965). The adsorption and kinetics of killing by colicin CA 42-E2. Australian Journal of Experimental Biology and Medical Science 43, 191200.

SABIK, J. F., SUIT, J. L. \& LuRIA, S. E. (1983). cea-kil operon of the ColEl plasmid. Journal of Bacteriology 153, 1479-1485.

Shafferman, A., Flashner, Y. \& Cohen, S. (1979). ColEl DNA sequences interacting in cis, essential for mitomycin $\mathrm{C}$ induced lethality. Molecular and General Genetics 176, 139-146. 
Sidraro, J. \& NowUra, M. (1974). Immunity substance. A protein from E3-colicinogenic cells that accounts for their immunity to colicin E3. Jowmal of Biological Chemistry 24, 445-453.

SUTCLIFFE, J. G. (1978). pBR322 restriction map derived from the DNA sequence: accurate DNA size markers up to 4361 nucleotide pairs long. Nucleic Acids Research 5, 2721-2727.

Tommassen, J., De Geus, P. \& Lugtenbaro, B. (1982). Regulation of the pho regulon of $E$. coli K12. Cloning of the regulatory genes phoB and phoR and identification of their gene products. Journal of Molecular Biology 157, 265-274.
VIEIRA, J. \& MEssing, J. (1982). The pUC plasmids, an M13 mp-7 derived system for insertion mutagenesis and sequencing with synthetic universal primers. Gene 19, 259-268.

Watson, R. \& VISENTIN, L. P. (1982). Cloning of the ColE3-CA38 colicin and immunity genes and identification of a plasmid region which enhances colicin production. Gene 19, 191-200.

Watson, R., Rowsoye, W., Tsho, J. \& Visentin, L. P. (1981). Identification and characterization of $\mathrm{Col}$ plasmids from classical colicin E-producing strains. Journal of Bacteriology 147, 569-577. 